\title{
Thermodynamics and Kinetics of Nanostructure Formation in Soft-Magnetic Nanocrystalline Alloys (Overview)
}

\author{
A. R. Yavari and O. Drbohlav \\ LTPCM-CNRS ura 29, BP 75, Institut National Polytechnique de Grenoble, Domaine Universitaire, \\ St-Martin-d'Herès 38402, France
}

\begin{abstract}
Thermodynamic and kinetic conditions for nanocrystallization of Fe-based amorphous precursors into a duplex structure of $\alpha$-Fe nanocrystals within a residual amorphous matrix are considered in view of recent literature. The effect of copper addition on nanograin size is explained in terms of the CuFe metastable phase diagram and the nature of the various heteroatomic interactions. Addition of larger atoms such as $\mathrm{Nb}$ and $\mathrm{Zr}$ that are rejected together with boron atoms at the $\alpha$-Fe nanocrystallization interface is found to generate diffusion double-layers with sharp concentration gradients. The diffusion double-layers explain measured differences in Curie temperatures $T_{\mathrm{c}}$ of the remaining grain boundary amorphous phase and bulk glasses of the same composition. They also successfully predict the occurence of a broad maximum in $T_{\mathrm{c}}$ of the remaining amorphous phase during nanocrystallization annealing. The concentration gradients have an additional thermodynamic stabilization effect on the amorphous interlayers by reducing the driving force for the formation of intermetallics.
\end{abstract}

(Received February 9, 1995)

Keywords: nanocrystallization, nanostructure, soft-magnetic, amorphous thermodynamics and kinetics, nucleation

\section{Introduction}

While simultaneous addition of $\mathrm{Cu}$ and $\mathrm{Nb}$ has long been known to induce grain refinement and improvement of low alloy steels as structural members ${ }^{(1)(2)}$, it was more recently discovered that their addition to $\mathrm{FeSiB}$ type glass-forming alloys results in the emergence upon annealing, of a nanocrystalline dispersion of $\alpha-\mathrm{Fe}(\mathrm{Si})$ particles with diameters of the order of $10 \mathrm{~nm}$ within a residual amorphous matrix with higher crystallization temperature due to $\mathrm{Nb}$ enrichment ${ }^{(3)}$. Such duplex nanostructures possess excellent soft-magnetic properties due to both an averaging effect of magnetocrystalline anisotropy and vanishing of over-all magnetostriction constants ${ }^{(3)}$.

The combined presence of $\mathrm{Nb}$ and $\mathrm{Cu}$ is actually not necessary for the nanocrystallization, if we define this process by the massive appearance of crystals of size near $50 \mathrm{~nm}$, since such nanostructures were observed long ago during crystallization of some near-eutectic or hypoeutectic Fe-based metallic glasses ${ }^{(4)}$. They can also be obtained by rapid annealing at higher temperatures using for example Joule-heating ${ }^{(5)}$. The presence of $\mathrm{Cu}$, which is presumed to assist nucleation of $\alpha$-Fe by clustering, and that of a slowly diffusing component such as the larger $\mathrm{Nb}$ (or $\mathrm{Ta}, \mathrm{V}, \mathrm{W}$..) atoms, to be rejected at the growing $\alpha-\mathrm{Fe}$ interfaces ${ }^{(6)}$, seem important for reducing the $\alpha$-Fe nanocrystal size down to 10 to $20 \mathrm{~nm}$ needed for the reduction of magneto-crystalline anisotropy and the consequent exceptionally high magnetic permeabilities ${ }^{(7)}$.

However, Cu-free FeMB amorphous alloys ${ }^{(8)(9)}$ (with $\mathrm{M}=\mathrm{Zr}, \mathrm{Hf}, \mathrm{Nb}$ ) have also been found to nanocrystallize into structures with excellent magnetic properties and higher magnetic induction due to higher $\mathrm{Fe}$ content. FeMC amorphous films were also found to nanocrystallize with appropriate heat treatment ${ }^{(10)}$. Furthermore, boron enrichment alone is known to sharply raise the crystallization temperature $T_{x}$ in FeB-type amorphous alloys $^{(11)}$ and its effect on sharply raising $T_{x}$ in the amorphous phase surrounding $\alpha$-Fe nanocrystals in FeZrBtype alloys has recently been demonstrated ${ }^{(12)}$.

In addition to these Fe-based nanocrystalline alloys with excellent soft-magnetic properties, very promising Al-based nanocrystalline alloys have also been obtained from amorphous precursors ${ }^{(13)}$.

Yet the nanocrystallization process responsible for the generation of these new materials is not well understood. In fact, uphill atomic diffusion characteristic of spinodal decomposition has been reported in FeZr alloys ${ }^{(14)}$ and recent evidence may suggest that spinodal decomposition in the amorphous phase sets the scale of the nanocrystallization in $\mathrm{FeZrB}$ alloys ${ }^{(15)}$. Furthermore in $\mathrm{FeSiBNbCu}$. glasses, the dimensions of the $\alpha$-Fe nanocrystals seem to be nearly independent of the annealing temperature until the onset of crystallization of the remaining amorphous matrix. However, it is unlikely that $\mathrm{Cu}$-additions usually near 1 at.\% and sometimes much less will reach beyond the spinodal composition as defined by $\partial G_{(\mathrm{am})}^{2} / \partial c_{\mathrm{Cu}}^{2}$ in a quaternary amorphous alloy in which the heat of mixing $\Delta H_{\text {mix }}$ of copper with some of the constituents is negative.

In this paper we will consider in more detail, the prominent metallurgical aspects and the thermodynamic and kinetic conditions of the nanocrystallization process that generates this important class of new materials. 


\section{Copper Addition and the Nanocrystallization of Fe-Based Amorphous Precursors}

Copper and iron interatomic interactions are repulsive and the $\mathrm{Cu}-\mathrm{Fe}$ binary system presents a classical case of mutual immiscibility in the solid state with the enthalpy of mixing $\Delta H_{\text {mix }} \approx+10.5 \mathrm{~kJ} / \mathrm{mol}^{(16)}$. Concentrated unstable $\mathrm{Cu}-\mathrm{Fe}$ alloys prepared by vapor deposition and mechanical alloying have been intensely studied recently ${ }^{(17)-(21)}$. It has been established that when non-equilibrium processing allows the formation of $\mathrm{CuFe}$ solid solutions, they are always bcc for $\mathrm{Cu}$-contents $x_{\mathrm{Cu}}<30$ at.\% and fcc for $x_{\mathrm{Cu}}>40$ at. $\%$ and amorphous phase formation has never yet been reported. Thus in a Cu-containing undercooled Fe-rich liquid or amorphous phase, when $\mathrm{Cu}$ atoms cluster into a region and reject $\mathrm{Fe}$ atoms into the surroundings, the local composition may go beyond the amorphization limit and form unstable $\mathrm{CuFe}$ nanocrystals.

In the case of $\mathrm{Nb}$-containing $\mathrm{Fe}$-based amorphous phases, $\mathrm{Nb}$ atoms will also be expelled since $\Delta H_{\text {mix }}$ $(\mathrm{CuNb})>0$ such that the local composition will leave the amorphization range while $x_{\mathrm{Cu}}<30$ at.\% and the resulting nanocrystals will have bcc structures. As such, they can serve as nucleation sites for the formation of $\alpha$-Fe embryos (It should be mentioned that while EXAFS studies of the $\mathrm{Cu}$-atom environment indicate presence of $\mathrm{fcc}$ nearest neighbor configurations ${ }^{(22)(23)}$, they appear to us to be consistent with the joint presence of fcc and bcc environments which might vary with cluster size).

Consider for example, the clustering of $\mathrm{Cu}$ atoms into such zones with radii $r_{\mathrm{Cu}-\text { rich }}=3 \mathrm{~nm}$ and take $x_{\mathrm{Cu}} \approx 30$ at. $\%$. For an initial composition with $1 \% \mathrm{Cu}$, there will be $\left[0.01 / x_{\mathrm{Cu}}(4 / 3) \pi r^{3}\right]$ such zones per $\mathrm{cm}^{3}$ separated by $\Delta l \approx 18 \mathrm{~nm}$ which is near the diameter of 10 to $20 \mathrm{~nm}$ of the $\alpha$-Fe after nanocrystallization.

Suppose now that instead of 3 at. $\% \mathrm{Nb}$, the FeB-based alloy contains $7 \% \mathrm{Zr}$. In this case zones of $\mathrm{Cu}$ clustering will not reject the $\mathrm{Zr}$ content. On the contrary, $\mathrm{Cu}-\mathrm{Zr}$ interactions are strongly attractive $\left(\Delta H_{\text {mix }}(\mathrm{CuZr}) \ll 0\right)$ and as $\mathrm{Cu}$-enriched zones reject $\mathrm{Fe}$ atoms, they are likely to attract $\mathrm{Zr}$ atoms. It is well known that $\mathrm{Cu}-\mathrm{Zr}$ alloys are easy glass-formers and remain so with some Fe content, since $\mathrm{Fe}-\mathrm{Zr}$ alloys also form glasses. $\mathrm{Cu}$-enriched zones in $\mathrm{Cu}$-containing $\mathrm{FeZrB}$ alloys will therefore remain within the amorphous phase composition limit. For ex-

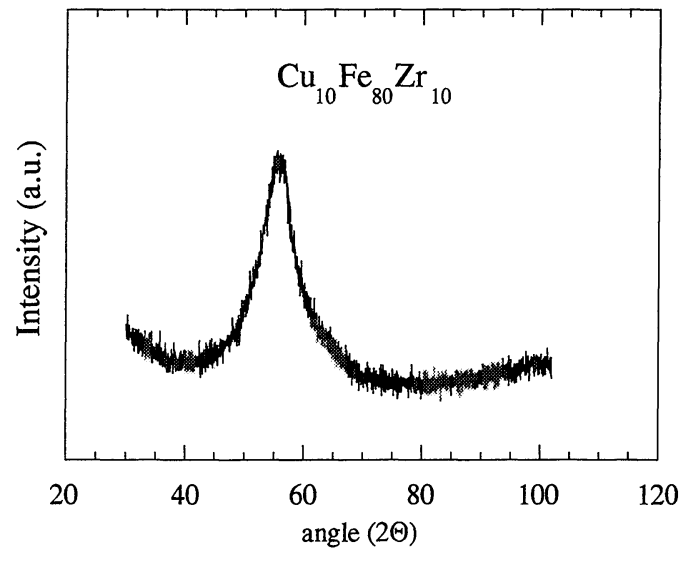

Fig. 1 X-ray diffraction pattern of amorphous $\mathrm{Fe}_{80} \mathrm{Cu}_{10} \mathrm{Zr}_{10}$.

ample, Fig. 1 shows the $\mathrm{X}$-ray diffraction pattern of amorphous $\mathrm{Fe}_{80} \mathrm{Zr}_{10} \mathrm{Cu}_{10}{ }^{(24)}$. There is thus no mechanism for $\mathrm{Cu}$ to form bcc zones by clustering in FeZrB alloys which nanocrystallizes without $\mathrm{Cu}^{(9)}$. However, the strongly positive $\Delta H_{\text {mix }}(\mathrm{CuFe})$ provides a thermodynamic driving force for $\mathrm{Cu}$-clustering and the creation of diffuse interfaces between $\mathrm{Cu}$-rich amorphous zones and the remaining Fe-rich amorphous phase. As such, the interfacial energy $(\sigma)$ contribution $4 \pi r^{2} \sigma$ of the $\alpha$-Fe nucleation free energy will be less at such interfaces than in the bulk of the amorphous alloy. With the critical nucleus radius given $r \approx 2 \sigma / \Delta G_{\text {cryst }}$ this effect leads to some grain refinement with $\mathrm{Cu}$ addition even in these alloys although the effect is less marked than in Nb-containing alloys where $\mathrm{Cu}$ clusters are expected to form the first bcc nanocrystals at the onset of the crystallization.

\section{Conditions for Primary Nanocrystallization of Fe-Based Near-Eutectic Alloys}

Nanocrystallization of ferromagnetic $\mathrm{Fe}$ - and Cobased amorphous alloys were observed by several research teams nearly 15 years ago. For example, Kulik and Matyja ${ }^{(25)}$ and Zaluska and Matyja ${ }^{(4)}$ respectively reported nanostructures in $\mathrm{CoSiB}$ and $\mathrm{FeSiB}$ alloys when the two crystallization stages for $\alpha$-Fe and intermetallic phase formation as detected by calorimetry were well separated. These nanostructures are seen in the TEM pictures of Fig. 2.

At that time the potential for very high magnetic per-
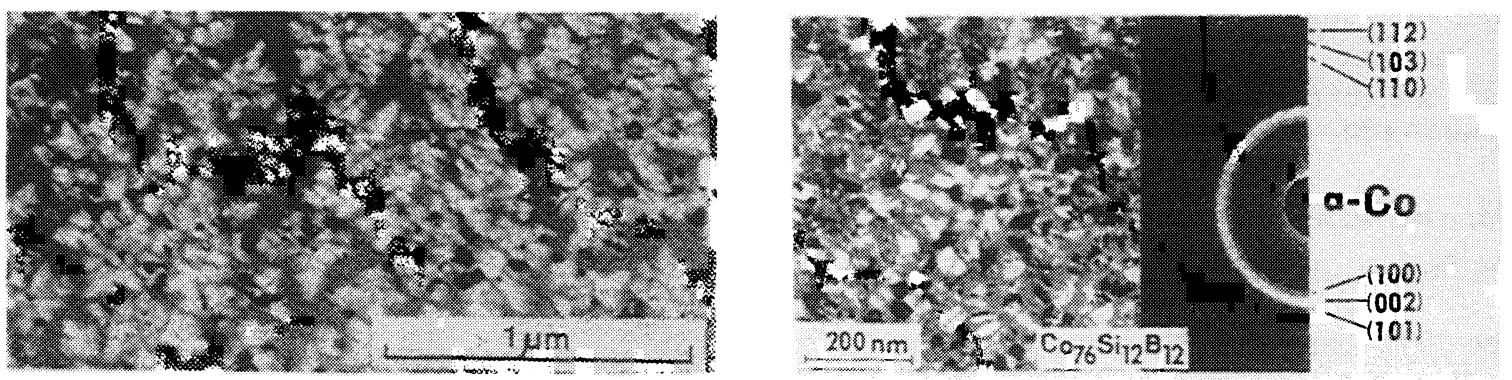

Fig. 2 Bright field TEM images of amorphous $\mathrm{Fe}_{84} \mathrm{Si}_{6} \mathrm{~B}_{10}$ (left) and $\mathrm{Co}_{76} \mathrm{Si}_{12} \mathrm{~B}_{12}$ (right) after primary crystallization ${ }^{(4)(25)}$. 
meabilities in these nanostructures was not known. Earlier, Walter ${ }^{(26)}$ had reported on the lowering of the temperature of nucleation of $\alpha-\mathrm{Fe}$ by $\mathrm{Pt}$ and $\mathrm{Au}$ and other elemental additions and the raising of the temperature of formation of intermetallics such as $\mathrm{Fe}_{2} \mathrm{~B}$ by $\mathrm{Nb}$, $\mathrm{Si}$ and other additions to $\mathrm{Fe}-\mathrm{B}$ based amorphous alloys.

Consider first the well known FeSiB amorphous alloys without other additions. As the temperature is raised, depending on the composition, $\alpha-\mathrm{Fe}(\mathrm{Si})$ crystals, $\mathrm{Fe}_{3} \mathrm{~B}$-type intermetallics or eutectic $\left(\alpha-\mathrm{Fe}(\mathrm{Si})+\mathrm{Fe}_{2} \mathrm{~B}\right)$ lamellar crystalline structures or $\mathrm{Fe}_{3} \mathrm{~B}$ will form. If the initial composition is hypoeutectic on the temperature composition metastable (undercooled) phase diagram, $\alpha-\mathrm{Fe}(\mathrm{Si})$ crystals will form first but have nearly no solubility for boron atoms which they reject into a surrounding diffusion layer. Since boron-enrichment raises the viscosity and the crystallization temperature of $\mathrm{FeSiB}$ amorphous alloys, the formation of a diffusion layer will slow the growth of the $\alpha-\mathrm{Fe}(\mathrm{Si})$ crystals thus allowing more time for the nucleation of other $\alpha$-crystallites before impingement and leads to the type of fine dispersion of 50 to $100 \mathrm{~nm}$ size crystallites of Fig. 2 within a residual amorphous matrix. We have expressed this process by the condition $\mathrm{d} T_{x} / \mathrm{d} C>0$ which holds if the element (here boron) rejected into the amorphous phase increases the latter's crystallization temperature ${ }^{(27)}$.

\section{Kinetic Effect of Addition of Slow-Diffusing Atoms with Low Solubility in $\alpha$-Fe}

We consider the copious nucleation of $\alpha-\mathrm{Fe}$ crystals during an appropriate isothermal anneal of an amorphous $\mathrm{FeSiB}$ or FeB-based alloy to which some $\mathrm{Nb}$ or $\mathrm{Zr}$ is added. As the $\alpha-\mathrm{Fe}(\mathrm{Si})$ nanocrystals grow, they reject niobium and boron atoms into the surrounding amorphous alloy whose viscosity increases (and atomic diffusion coefficient decreases) with $\mathrm{Nb}$-enrichment $\left(\mathrm{d} T_{x} /\right.$ $\mathrm{d} C_{\mathrm{Nb}}>0$ ) and crystallization temperature increases (see $\mathrm{Nb}$-concentration dependence of $T_{x}$ in Fig. 3). As a Nbrich diffusion layer forms around the emerging $\alpha-\mathrm{Fe}$ nanocrystals, it arrests their growth and further annealing in the temperature range of nanocrystallization has little effect on size of such $\alpha$-Fe nanocrystals ${ }^{(28)-(30)}$ and only increases their volume fraction until a metastable equilibrium with the surrounding amorphous phase is reached if intermetallics do not nucleate ${ }^{(27)}$.

For amorphous alloys such as $\mathrm{Fe}_{74.5} \mathrm{Si}_{13.5} \mathrm{~B}_{9} \mathrm{Nb}_{2.25} \mathrm{Cu}_{0.75}$, the results of detailed magnetic, $\mathrm{X}$-ray diffraction, microscopic and FIM studies ${ }^{(28)(29)(31)}$, have shown that $\alpha$-Fe particles emerging from the $\mathrm{FeSiB}+\mathrm{Nb}$ amorphous phase have a composition near $\mathrm{Fe}_{80} \mathrm{Si}_{20}$ which through mass balance yields the reaction:

$$
\begin{aligned}
& \mathrm{Fe}_{74.5} \mathrm{Si}_{13.5} \mathrm{~B}_{9} \mathrm{Nb}_{2.25} \mathrm{Cu}_{0.75} \rightarrow \\
& 0.7 \mathrm{Fe}_{80} \mathrm{Si}_{20 \text { (nanocryst) }}+0.3 \mathrm{Fe}_{62} \mathrm{~B}_{30} \mathrm{Nb}_{8(\mathrm{am})}+0.0075 \mathrm{Cu}
\end{aligned}
$$

where the $70 \%$ share of the $\alpha$-phase is confirmed experimentally and the amorphous grain-boundary phase is found to have a global composition of $\mathrm{Fe}_{62} \mathrm{~B}_{30} \mathrm{Nb}_{8}$.
However, inspite of the $30 \%$ share of the volume, the remaining amorphous phase provides a weak contribution to the saturation magnetization and its detected Curie temperature $T_{\mathrm{c}}$ values are too high to correspond to that of the predicted composition. The metastable equilibrium of the type given in eq. (1) fixes the global concentration of the remaining amorphous phase whose crystallization $T_{x}$ (see second DSC peak of Fig. 6) and Curie temperatures $T_{\mathrm{c}}$ have been measured within the duplex structure. However when compositions near that of the remaining amorphous phase of eq. (1) are prepared in the bulk, they systematically show $T_{\mathrm{c}} \mathrm{s}$ that are nearly 200 degrees too low ${ }^{(32)}$. In view of the controlling effect of $\mathrm{Nb}$-content on these properties as demonstrated in Fig. 3, it appears ${ }^{(32)}$ that the remaining amorphous phase behaves as if its niobium content were about half of the value indicated by mass balance. (Here we have not indicated the Si content of the different alloys containing $\mathrm{Nb}, \mathrm{B}$ and Si because of the predominant effect of $\mathrm{Nb}$ on $T_{\mathrm{c}}$, the Si-content variations explaining the scatter in the data, but all compositions are given elsewhere ${ }^{(27)(32)}$ ). We have resolved this apparent discrepancy by considering the sharp $\mathrm{Nb}$ concentration gradient that is expected to build up ahead of the nanocrystallization fronts ${ }^{(27)}$. The excess solute content ( $\mathrm{Nb}$ and $\mathrm{B}$ atoms for example) will accumulate in diffusion layers of thickness $L \approx$ $\left(D_{\mathrm{i}} t\right)^{1 / 2}$ ahead of the crystallization interfaces where $D_{\mathrm{i}}$ are the diffusivities of the rejected species in the surroundings.

It has been empirically established that the activation energy for atomic diffusion in amorphous alloys scales with the atomic volume $V$ of the diffusing atom ${ }^{(33)}$. The atomic volume of boron being much smaller than that of $\mathrm{Nb}, D_{\mathrm{B}}$ is expected to be several orders of magnitude larger than $D_{\mathrm{Nb}}$. In the case of $\mathrm{FeSiBNbCu}$ amorphous precursors, nanostructures with optimum soft-magnetic properties are obtained after annealing near $500^{\circ} \mathrm{C}$. While no values are currently available for $\mathrm{Nb}$ diffusion in amorphous FeSiB, $D_{\mathrm{Nb}\left(500^{\circ} \mathrm{C}\right)}$ in $\alpha-\mathrm{Fe}$ is $5 \times 10^{-20} \mathrm{~m}^{2} / \mathrm{s}^{(34)}$, tracer diffusivity $D_{\mathrm{Zr}\left(500^{\circ} \mathrm{C}\right)}$ of $\mathrm{Zr}$ in amorphous $\mathrm{Fe}_{91} \mathrm{Zr}_{9}$ is about $10^{-20} \mathrm{~m}^{2} / \mathrm{s}^{(35)}, D_{\mathrm{Fe}\left(500^{\circ} \mathrm{C}\right)} \approx 10^{-18} \mathrm{~m}^{2} / \mathrm{s}$ in $\mathrm{FeSiB}^{(36)}$

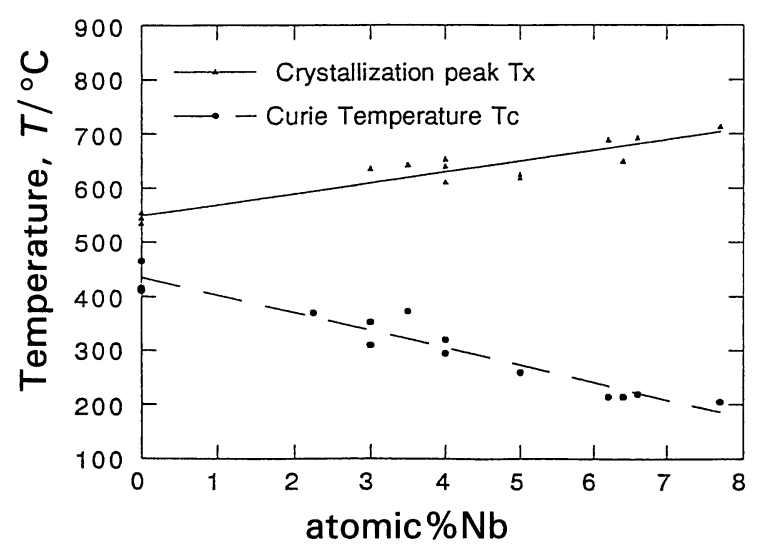

Fig. 3 Variation of crystallization peak temperature $T_{x}$ and Curie temperature $T_{\mathrm{c}}$ with $\mathrm{Nb}$ content in $\mathrm{FeB}(\mathrm{Si})$ amorphous alloys ${ }^{(32)}$ with the $\mathrm{Si}$ and $\mathrm{B}$ content variations explaining the scatter in the data. 
and the data on diffusivity of B in FeB-based amorphous alloys presented by Cahn et al. ${ }^{(37)}$ indicate that $D_{\mathrm{B}\left(500^{\circ} \mathrm{C}\right)}$ $\geq 10^{-15} \mathrm{~m}^{2} / \mathrm{s}$. We can therefore use, as a first approximation, $D_{\mathrm{B}} / D_{\mathrm{Nb}} \geq 10^{4}$. With this ratio, the diffusion layers of the boron $L_{\mathrm{B}} \approx\left(D_{\mathrm{B}} t\right)^{1 / 2}$ and $\mathrm{Nb}$ atoms $L_{\mathrm{Nb}} \approx\left(D_{\mathrm{Nb}} t\right)^{1 / 2}$ ahead of the $\alpha$-Fe nanocrystallization front may be schematically drawn as in Fig. 4.

This means that as the nanocrystals of $\alpha-\mathrm{Fe}(\mathrm{Si})$ nucleate and grow to dimensions that result in the impingment of their diffusion layers, the much faster diffusing boron atoms should have a flat concentration profile in the grain-boundary amorphous layers while the large, slow diffusing $\mathrm{Nb}$ atoms should exhibit a sharp concentration profile with $\mathrm{Nb}$ accumulation at the $\alpha$-nanocrystal/amorphous phase interfaces as drawn in Fig. 5. This situation corresponds to the nanocrystallization stage when further annealing results in no further growth of the $\alpha$ nanocrystal phase fraction as referred to earlier. Since $D_{\mathrm{B}} \gg D_{\mathrm{Nb}}$, the Nb-rich interfacial diffusion layer will be much thinner than the B-rich, Nb-poor central zone with concentrations still near the initial $\mathrm{Nb}$ content of 2 to 3 at\%. For an amorphous interlayer of for example $3 \mathrm{~nm}$ in thickness, the boron-rich $\mathrm{Nb}$-poor central zone should be more than $2.8 \mathrm{~nm}$ thick. When the magnetic properties of this grain boundary phase with a global concentration $\mathrm{Fe}_{62} \mathrm{~B}_{30} \mathrm{Nb}_{8}$ as per eq. (1) are measured, the detected Curie temperature $T_{\mathrm{c}}$ will be that of this Nb-poor central zone with much higher $T_{\mathrm{c}}$ than that of an amorphous alloy corresponding to the global composition. The contri-

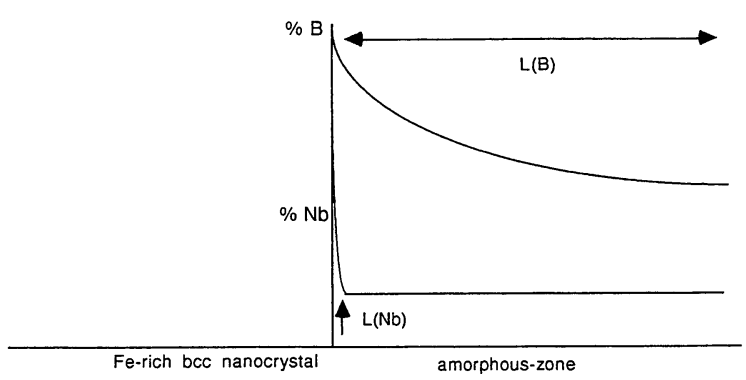

Fig. $4 \mathrm{~B}$ and $\mathrm{Nb}$ atoms rejected at the crystallization front forming diffusion layers of thickness $L \approx\left(D_{\mathrm{Nb}} t\right)^{1 / 2}$ and $L \approx\left(D_{\mathrm{B}} t\right)^{1 / 2}$ in the surrounding amorphous matrix.

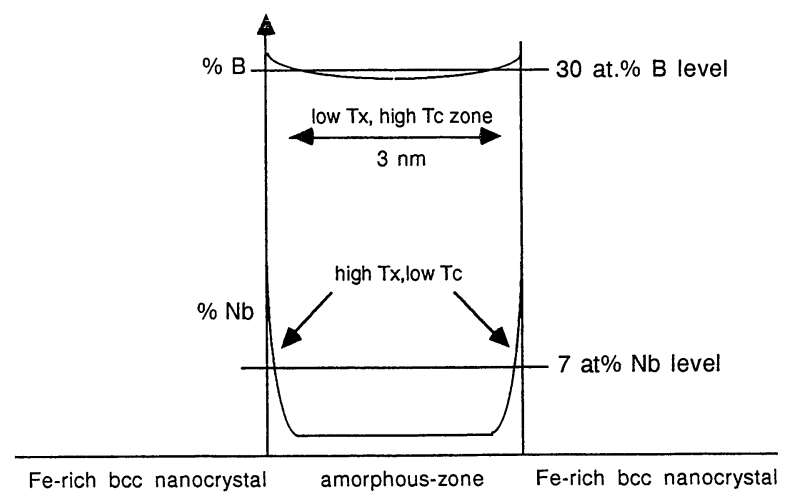

Fig. 5 Schematic boron and niobium concentration profiles in the amorphous grain boundary layer at the end of nanocrystallization.

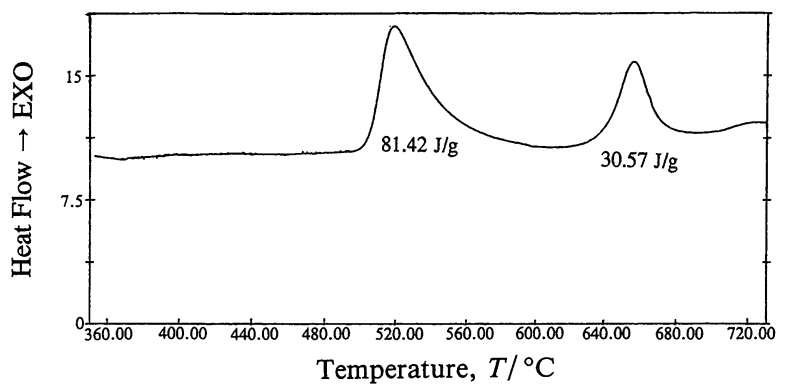

Fig. 6 DSC thermogram of amorphous $\mathrm{Fe}_{74.5} \mathrm{Si}_{13.5} \mathrm{~B}_{9} \mathrm{Nb}_{2.25} \mathrm{Cu}_{0.75}$ (heating rate $20 \mathrm{~K} / \mathrm{min})^{(32)}$.

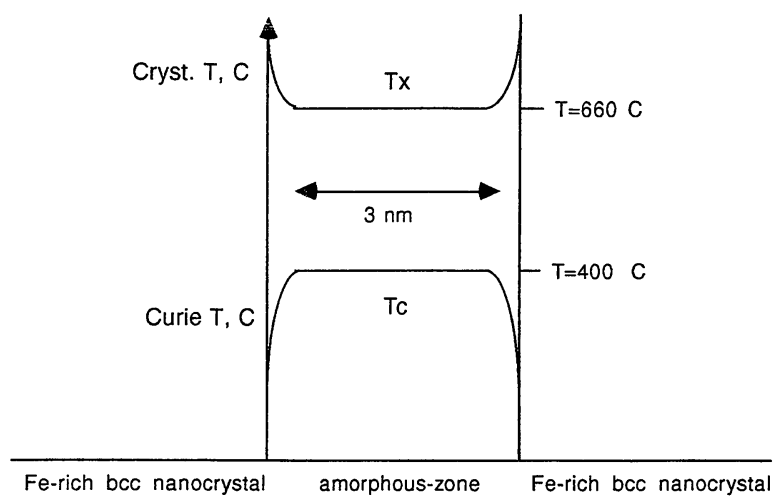

Fig. 7 Expected Curie temperature $T_{\mathrm{c}}$ and crystallization temperature $T_{x}$ profiles in the amorphous grain boundary layer at the end of nanocrystallization.

bution of the $\mathrm{Nb}$-rich interfacial zone will be very weak or paramagnetic but it is so thin that it can be neglected as a magnetic spacer. Thus, for the alloy of eq. (1), the measured $T_{\mathrm{c}}$ will match that of an alloy with the expected B-content of $30 \%$ but with only about 2.25 at.\% Nb. The crystallization temperatures $T_{x}$ of alloys near this composition also match closely the position of the second DSC peak of Fig. 6. This situation is schematically represented in Fig. 7. Therefore, by taking account of the expected sharp niobium profile in the remaining amorphous grain-boundary phase, it is possible to successfully explain differences between the properties of this grainboundary amorphous phase and those of the same global composition in the bulk.

\section{Thermodynamic Stabilization Role of Addition of Slow-Diffusing Atoms with Low Solubility in $\alpha$-Fe}

The condition of the type $\mathrm{d} T_{x} / \mathrm{d} C_{\mathrm{Nb}}>0$ implies that the crystallization temperature of the solute-rich diffusion layer is even higher than the already increased $T_{x}$ of the expected global grain boundary amorphous layer composition and kinetically delays nucleation of intermetallics in the diffusion layer. However, such diffusion layers also inhibit the appearance of intermetallic phases thermodynamically.

Figure 8 shows free energy curves for nucleation of a 
crystalline intermetallic phase when an amorphous phase subjected to a strong concentration gradient is heated to crystallization. If the nucleus of the intermetallic is to form in this situation, the concentration gradient will also exist in the intermetallic nucleus. In Fig. 8 it can be seen that if the shaded areas above the free energy curve of the amorphous phase are larger than the shaded area below it, $\Delta G$ (amorphous $\rightarrow$ crystal) will be positive and no driving force will exist for crystallization. This situation occurs depending on the sharpness of the concentration gradient and on the curvature of the $G$-curve of the intermetallic, meaning that it is more likely to occur for line compounds. It is also more likely to occur on or near the $\alpha$-nanocrystals' growing interfaces where sharp gradients develop and thus disallow heterogeneous nucleation of the intermetallic on the $\alpha$-phase. This effect provides added stability to the amorphous layer in which the concentration gradient must be flattened by diffusion before nucleation of the intermetallics can occur.

Detailed consideration of effects of sharp concentration gradients have been presented elsewhere ${ }^{(38)}$. In the case of the $\mathrm{Nb}$-containing example given above, the $T_{x}$ of bulk composition that best matches the measured Curie temperature $T_{\mathrm{c}}$ of the remaining grain-boundary phase is indeed somewhat lower than $T_{x}$ of the latter. This could indicate that contrary to bulk $\mathrm{FeSiB}$ amorphous alloys that usually begin crystallization on their surfaces, the grain-boundary amorphous layer's crystallization may

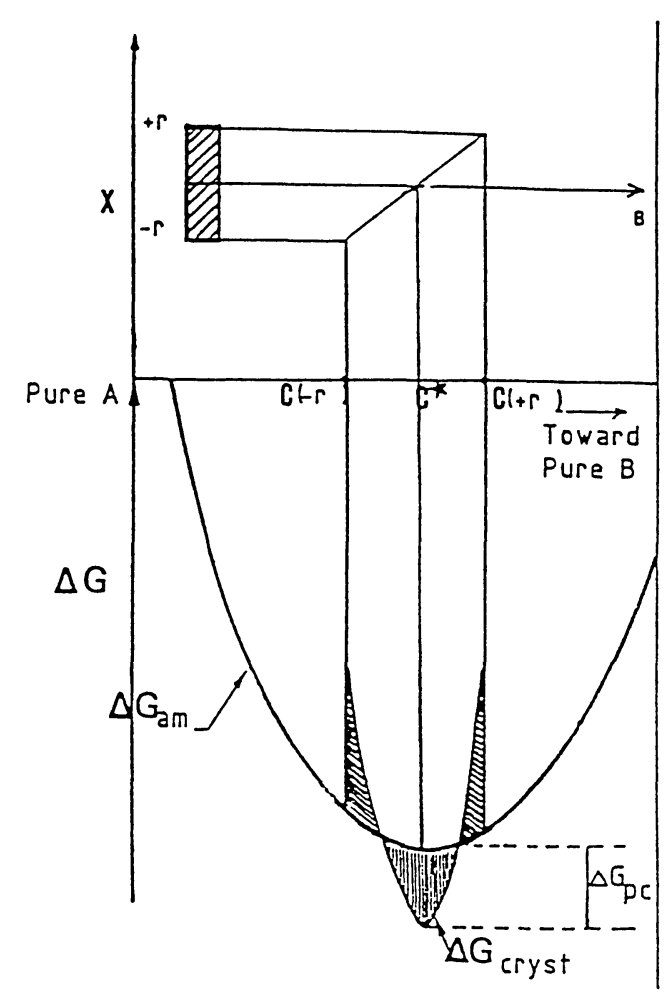

Fig. 8 Schematic drawing of a critical-sized nucleus from $-r$ to $r$ along a concentration gradient $\Delta C$. If the shaded areas above the free energy curve of the amorphous phase are larger than the shaded area below it, $\Delta G$ (amorphous $\rightarrow$ crystal) will be positive and no driving force will exist for crystallization. begin homogeneously in its central zone away from the $\alpha$-Fe nanocrystal interfaces due to the sharp $\mathrm{Nb}$ concentration gradient.

\section{Concentration Gradient-Induced Maximum in the Curie Temperature $T_{\mathrm{c}}$ of the Amorphous Phase during Nanocrystallization}

The much faster diffusion of boron atoms compared to niobium (or zirconium..) atoms rejected at the $\alpha$-Fe nanocrystallization fronts into the surrounding amorphous phase, the resulting diffusion layers of very different thicknesses and the resulting Curie temperature of the remaining amorphous phase dominated by the boron diffusion layer were discussed in connection with the schematic drawings of Figs. 4, 5 and 7. Since the rejected boron atoms spread first into the remaining amorphous phase and $\mathrm{d} T_{\mathrm{c}} / \mathrm{d} c_{\mathrm{B}}>0$, the Curie temperature $T_{\mathrm{c}}$ of the amorphous phase must first increase with annealing time. Subsequently, for longer annealing times and after the concentration profile of boron atoms has become flat, the slower $\mathrm{Nb}$ atoms also rejected by $\alpha$-Fe nanocrystals will spread out further into the remaining amorphous phase and since $\mathrm{d} T_{\mathrm{c}} / \mathrm{d} c_{\mathrm{Nb}}<0, T_{\mathrm{c}}$ of the amorphous phase must decrease thus creating a broad maximum in the curve for $T_{\mathrm{c}}(\mathrm{am})$ versus annealing time. Ignoring the effects of Si variations compared to those of $\mathrm{Nb}$ and $\mathrm{B}$ gradients as explained for Fig. 3, such data have in fact been obtained during nanocrystallization annealing of the amorphous $\mathrm{Fe}_{73.5} \mathrm{Si}_{13.5} \mathrm{~B}_{9} \mathrm{Nb}_{3} \mathrm{Cu}_{1}$ alloy as shown in Fig. 9 from the work of Kaloshkin et al. ${ }^{(39)}$. While the absolute scale of their $T_{\mathrm{c}}$ values here is somewhat high compared to other reports, these authors independently explained the time dependence with the same reasoning as ours.

The $T_{\mathrm{c}}(\mathrm{am})$ maximum is more clearly seen by the schematic concentration path followed during annealing by the remaining amorphous phase in Fig. 10 which plots $T_{\mathrm{c}}(\mathrm{am})$ as a function of both $\mathrm{B}$ and $\mathrm{Nb}$-atom contents ${ }^{(40)}$. Some scatter exists because of the assimilation of $\mathrm{Si}$ atoms in the B-count for $\mathrm{FeSiB}$ alloys presented in this figure.

Consistent with a similar effect of B and Ta diffusion

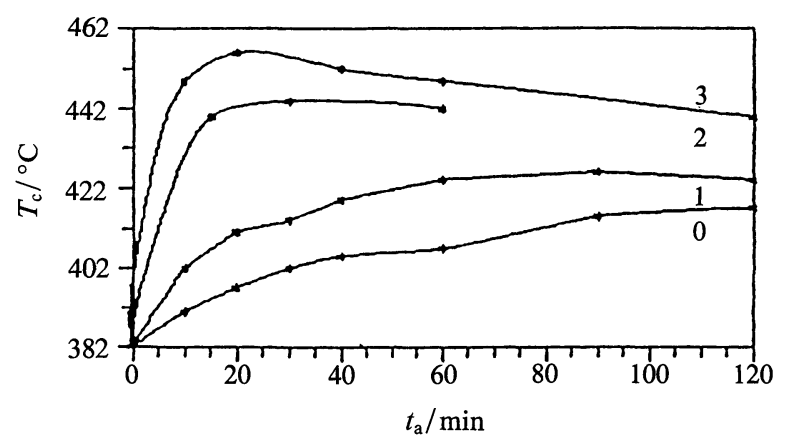

Fig. 9 Curie temperature $T_{\mathrm{c}}(\mathrm{am})$ of the amorphous precursor $\mathrm{Fe}_{73.5} \mathrm{Si}_{13.5} \mathrm{~B}_{9} \mathrm{Nb}_{3} \mathrm{Cu}_{1}$ during nanocrystallization annealing at $(0)$ $-500^{\circ} \mathrm{C},(1)-525^{\circ} \mathrm{C},(2)-550^{\circ} \mathrm{C}$ and $(3)-575^{\circ} \mathrm{C}^{(39)}$. 


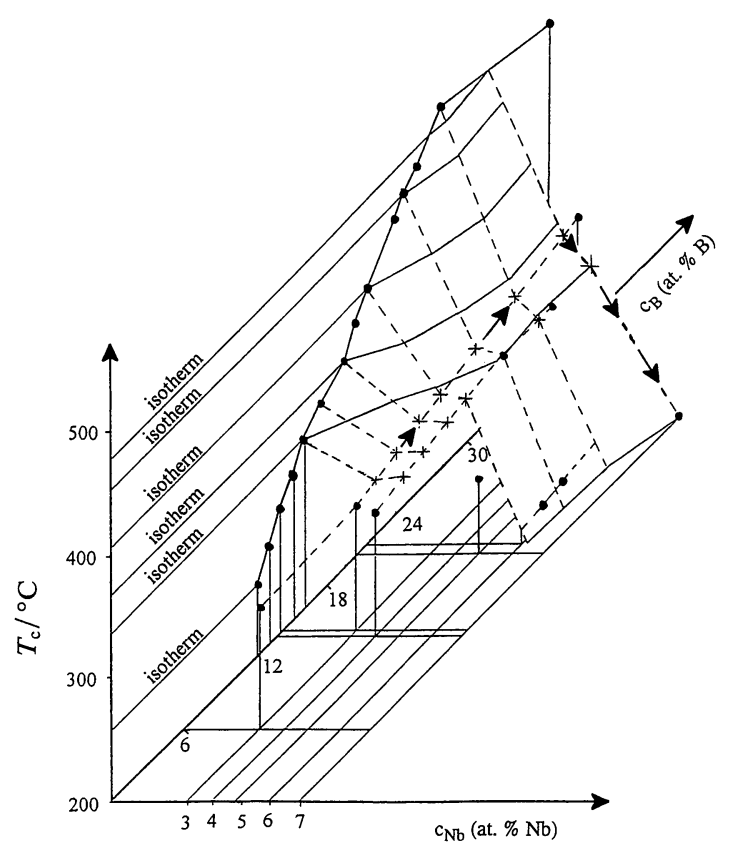

Fig. $10 T_{\mathrm{c}}(\mathrm{am})$ as a function of both $\mathrm{B}$ and $\mathrm{Nb}$-atom content in FeSiBNb amorphous alloys $(\bullet)$ measured, $(\times)$ extrapolated from measured points. The arrows schematically indicate the path followed by $T_{\mathrm{c}}$ of the $\mathrm{Fe}_{73.5} \mathrm{Si}_{13.5} \mathrm{~B}_{9} \mathrm{Nb}_{3} \mathrm{Cu}_{1}$ amorphous precursor during nanocrystallization annealing. Si-content variations (not plotted) generate some scatter but do not change the trends ${ }^{(32)}$.

layers, $T_{\mathrm{c}}(\mathrm{am})$ of an amorphous $\mathrm{Fe}_{73.5} \mathrm{Ta}_{3} \mathrm{Si}_{13.5} \mathrm{~B}_{9} \mathrm{Cu}_{1}$ alloy was also reported ${ }^{(41)}$ to increase with the onset of nanocrystallization, from an as-quenched value of $325 \mathrm{~K}$ to $T_{\mathrm{c}}=380^{\circ} \mathrm{C}$ after annealing at $520^{\circ} \mathrm{C}$ before decreasing to a low $T_{\mathrm{c}}=296^{\circ} \mathrm{C}$ after annealing at $580^{\circ} \mathrm{C}$. The maximum of the coercivity versus temperature in this alloy was found to move up to several tens of degrees above the Curie temperature $T_{\mathrm{c}}(\mathrm{am})$ of the remaining amorphous phase that acts as a spacer between the $\alpha-\mathrm{Fe}(\mathrm{Si})$ crystallites which are still ferromagnetic at $T>T_{\mathrm{c}}(\mathrm{am})$. The onset of this effect, which was attributed to exchange interactions across the amorphous paramagnetic spacer ${ }^{(42)}$ and the onset of superparamagnetism in these two-phase nanostructures are therefore also influenced by the sharp concentration gradients that modify $T_{\mathrm{c}}(\mathrm{am})^{(43)}$.

\section{Conclusions}

The above analysis of thermodynamic and kinetic conditions for nanocrystallization of Fe-based amorphous precursors allows the following conclusions:

(1) Nanocrystallization of Fe-based amorphous alloys does not require $\mathrm{Nb}, \mathrm{Zr}$ or $\mathrm{Cu}$ additions. Fe-based hypoeutectic alloys can form a duplex structure of $\alpha$-Fe nanocrystals within a residual amorphous matrix provided that emerging $\alpha$-Fe nanocrystals reject a component i for which $\mathrm{d} T_{x}(\mathrm{am}) / \mathrm{d} C_{\mathrm{i}}>0$.

(2) The effect of copper addition on nanograin size is explainable through the formation of diffuse interfaces between the Fe-rich amorphous phase and amorphous
$\mathrm{Cu}$-rich clusters on which $\alpha$-Fe nanocrystals can nucleate with reduced interfacial energy. The stronger nucleating effect of $\mathrm{Cu}$-addition in $\mathrm{Nb}$-containing FeB-based alloys is explained in terms of the $\mathrm{CuFe}$ metastable phase diagram which indicates that $\mathrm{Cu}$-enriched clusters in these alloys should crystallize in bcc structure.

(3) Addition of larger atoms such as $\mathrm{Nb}$ and $\mathrm{Zr}$ that are rejected together with boron atoms at the $\alpha-\mathrm{Fe}$ nanocrystallization interface is found to generate diffusion double-layers with sharp concentration gradients. The diffusion double-layers explain measured differences in Curie temperatures $T_{\mathrm{c}}$ of the remaining grain boundary amorphous phase and bulk glasses of the same composition. They also successfully predict the occurence of a broad maximum in $T_{\mathrm{c}}$ of the remaining amorphous phase during nanocrystallization annealing. The concentration gradients have an additional thermodynamic stabilization effect on the amorphous interlayers by reducing the driving force for the formation of intermetallics.

\section{REFERENCES}

(1) J. L. Hurley and C. H. Shelton: Met. Eng. Quart., 6 (1966), 25.

(2) M. R. Krishnadev and A. Galibois: Met. Trans., 6A (1975), 222.

(3) Y. Yoshizawa, S. Oguma and K. Yamauchi: J. Appl. Phys., 64 (1988), 6044.

(4) A. Zaluska and H. Matyja: Proc. Rapidly Quenched Metals IV, Ed. by T. Masumoto and K. Suzuki, Japan Inst. Metals, (1982), p. 683.

(5) T. Kulik, T. Horubala and H. Matyja: Mater. Sci. \& Eng., A157 (1992), 10.7.

(6) C. H. Moon and S. J. Kim: Scripta Metall. Mater., 31 (1994), 1325.

(7) G. Herzer: IEEE Trans. Mag., 25 (1989), 3327.

(8) K. Suzuki, A. Makino, A. Inoue and T. Masumoto: J. Appl. Phys., 70 (1991), 6232.

(9) A. Inoue: Mater. Sci. Forum, 179-181 (1995), in press.

(10) N. Hasegawa and M. Saito: J. Magn. Soc. Jpn., 14 (1990), 313.

(11) R. Hasegawa and R. Ray: J. Appl. Phys., 49 (1978), 4174.

(12) K. Suzuki, A. Makino, A.-P. Tsai, A. Inoue and T. Masumoto: Mater. Sci. \& Eng., A179/180 (1994), 501.

(13) Y. H. Kim, A. Inoue and T. Masumoto: Mater. Trans., JIM, 31 (1990), 747.

(14) N. Karpe, J. Bottiger, A. L. Greer, J. Janting and K. K. Larsen: J. Mater. Res., 7 (1992), 926.

(15) K. Kim, T. H. Noh, I. K. Kang and T. Kang: Mater. Sci. \& Eng., A179/180 (1994), 552.

(16) L. Kaufman: CALPHAD, 2 (1978), 117.

(17) K. Sumiyama and Y. Nakamura: J. Mag. Mag. Mater., 35 (1983), 219.

(18) K. Sumiyama, T. Yoshitake and Y. Nakamura: J. Phys. Soc. Jap., 9 (1984), 3160.

(19) P. H. Shingu, K. N. Ishihara, K. Uenishi, J Kuyama, B. Huang and S. Nasu: Solid State Powder Processing, Ed. by A. H. Clauer and J. J. de Barbadillo, Min., Met. and Mater. Soc., (1990), p. 21.

(20) K. Uenishi, K. F. Kobayashi, K. N. Ishihara and P. H. Shingu: Z. Metallk., 83 (1992), 132.

(21) A. R. Yavari, P. Desré and T. Benameur: Phys. Rev. Lett., 68 (1992), 2235.

(22) J. D. Ayers, V. G. Harris, J. A. Sprague and W. T. Elam: IEEE Trans Mag., 29 (1993), 2664.

(23) M. Sakurai, M. Matsuura, S.-H. Kim, Y. Yoshizawa, K. Yamauchi and K. Suzuki: Mater. Sci. \& Eng., A179/A180 (1994), 469.

(24) O. Drbohlav, B. Bochu, A. R. Yavari, M.-D. Baro and S. Surinach: Mater. Sci. Forum, 179-181 (1995), in press.

(25) T. Kulik and H. Matyja: Proc. Rapidly Quenched Metals IV, 
Ed. by T. Masumoto and K. Suzuki, Japan Inst. Metals, (1982), p. 659.

(26) J. L. Walter: Mater. Sci. \& Eng., 50 (1981), 137.

(27) A. R. Yavari: Proceedings of IV International Workshop on NonCrystalline Solids, (Sept. 1994 Madrid), Ed. by A. Hernando and M. Vazquez, in press.

(28) M. Muller, N. Mattern and L. Illgen: J. Mag. Mag. Mat., 112 (1992), 263.

(29) M. Muller, N. Mattern and L. Illgen: Z. Metallk., 82 (1991), 895.

(30) T. Kulik and A. Hernando: Mater. Sci. Forum, 179-181 (1995), in press.

(31) K. Hono, K. Hiraga, Q. Wang, A. Inoue and T. Sakurai: Acta Metall. Mater., 40 (1992), 2137.

(32) A. R. Yavari, G. Fish, S. K. Das and L. A. Davis: Mater. Sci. \& Eng., A181/A182 (1994), 1415.

(33) A. L. Greer, N. Karpe and J. Bottiger: J. Alloys and Compounds, 194 (1993), 199.

(34) U. Koster, U. Schunemann, M. Blank-Bewersdroff, S. Bauer, M. Sutton and G. B. Stephenson: Mater. Sci. \& Eng., A133 (1991)
611.

(35) J. Horvath, J. Ott, K. Pfahler and W. Ulfert: Mater. Sci. \& Eng., 97 (1988), 409.

(36) H. Kronmüller and W. Frank: Rad. Eff. \& Def. in Solids, 108 (1989), 81.

(37) R. W. Cahn, J. E. Evetts, J. Patterson, R. E. Somekh and C. K. Jackson: J. Mater. Sci., 15 (1980), 702.

(38) P. J. Desré and A. R. Yavari: J. Alloys and Compounds, 194 (1993), 229.

(39) S. D. Kaloshkin, I. A. Tomilin, B. V. Jalnin, I. B. Kekalo and E. V. Shelekhov: Mater. Sci. Forum, 179-181 (1995), in press.

(40) O. Drbohlav: Ph.D. Thesis, Institut National Polytechnique de Grenoble, 1995.

(41) T. Kulik and A. Hernando: J. Magn. Mag. Mater., 138 (1994), in press.

(42) A. Hernando and T. Kulik: Phys. Rev., B 49 (1994), 7064.

(43) A. Hernando, I. Navarro and P. Gorria: Phys. Rev., B 51 (February 1995), $\mathrm{n}^{\circ} 5$, in press. 